\title{
DESAIN BELT CONVEYOR UNTUK PENCURAHAN MATERIAL DENGAN KAPASITAS 125 TON PER JAM, LEBAR SABUK 400 MM DAN VOLUME ANGKUT 96,154 TON PER JAM
}

\author{
Farizal \\ Dosen Tetap pada Program Studi Teknik Industri \\ Fakultas Teknik Unversitas Tulang Bawang \\ Hamimi \\ Dosen Tetap pada Program Studi Teknik Elektro \\ Fakultas Teknik Unversitas Muhammadiyah Lampung
}

\begin{abstract}
Abstrak
Pesawat angkat jenis hoesting machine dipergunakan ntuk mengangkat atau memindahkan muatan yang berjumlah tertentu secara sekaligus. Jenis ini meliputi antara lain crane, wrench, dongkrak, dan sebagainya, sedangkan jenis conveying machine diperguakan untuk memindahkan atau mengangkat muatan dalam satuan unit dan berlangsung kontinyu atau terus-menerus.

Berdasarkan hasil penelitian belt conveyor didapatkan data sebagai berikut: a. Kapasitas (kapasitas angkut (Q) 125 ton/jam, kapasitas per meter (g) 0,0434 ton/m, volume angkut

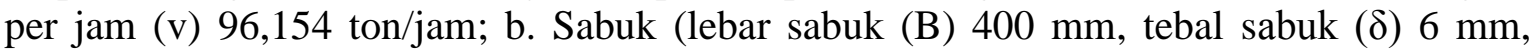
panjang sabuk $22.000 \mathrm{~mm}$ ); c. Puli (diameter puli (Dp) $375 \mathrm{~mm}$, panjang puli (Lp) 500 mm, putaran puli $\left(\mathrm{n}_{\mathrm{p}}\right) 40 \mathrm{rpm}$; d. Rol penumpu (diameter (Dr) $108 \mathrm{~mm}$, panjang (Lr) 500 $\mathrm{mm}$; d. Frame (standarisasi SII.0233-79, baja canai bertepi bulat canai panas dengn simbol V-60, bahan BJ34); e. Motor penggerak (motor listrik merk HITACHI, tipe TFC, 3-phase 200-600V, 50/60 Hz IEC Standard, frame size TFOL - $132 \mathrm{MF}$, daya output: 7,5 Kw - 4 pole, putaran $800 \mathrm{rpm}$ ); f. Reduction Gear (merk produksi bellpony, perbandingan transimisi 1/20, daya input $17,82 \mathrm{Kw}$, tipe PA 50, putaran input $800 \mathrm{rpm}$ ).
\end{abstract}

Kata kunci: disain, belt conveyor, pencurahan material, kapasitas, lebar sabuk, volume angkut

\section{DESIGN CONVEYOR BELT FOR MATERIAL STORAGE WITH CAPACITIES 125 TON PER HOUR, WIDTH BY 400 MM AND VOLUME TRANSFER 96,154 TON PER HOUR}

\author{
Farizal \\ Permanent Lecturer of Industrial Engineering \\ Engineering Faculty of Tulang Bawang University \\ Hamimi \\ Permanent Lecturer of Electrical Engineering \\ Engineering Faculty of Muhammadiyah Lampung University
}

\begin{abstract}
Machine type lift plane is used to lift or move a certain amount of payloads simultaneously. This type includes cranes, wrench, jack, and so on, while the conveying machine type is used to move or lift the charge in unit units and continuous or continuous Based on the research result belt conveyor obtained data as follows: a. Capacity (transport capacity $(Q)$ 125 ton / hour, capacity per meter ( $g$ ) 0.0434 ton / $\mathrm{m}$, volume per hour (v) 96,154 ton / $h$,

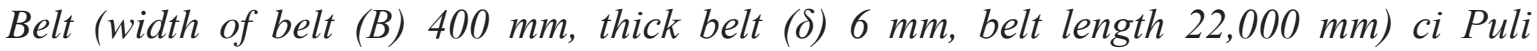


(diameter of pulp (Dp) $375 \mathrm{~mm}$, length of pulp (Lp) $500 \mathrm{~mm}$, rounds of pulp (np) $40 \mathrm{rpm}$; $108 \mathrm{~mm}$, length (Lr) $500 \mathrm{~mm}$, d) Frame (standardization SII.0233-79, round-rolled hot rolled steel with V-60 symbol, BJ34 material) e) propellant motor (electric motor HITACHI, TFC type, 3-phase 200-600V, 50/60 Hz IEC Standard, frame size TFOL - 132 MF, output power: $7.5 \mathrm{Kw}-4$ pole, $800 \mathrm{rpm}$ rotation), Reduction Gear (brand bellpony production, 1 /20, input power $17.82 \mathrm{Kw}$, type PA 50, input round $800 \mathrm{rpm}$ ).

Keywords: design, belt conveyor, material outpouring, capacity, belt width, transportation volume

\section{Pendahuluan}

\subsection{Latar Belakang}

Alat penangkat adalah suatu alat yang dipergunakan untuk memindahkan benda dari suatu tempat ke tempat lain yang diinginkan. Alat ini bannyak digunakan secara luas di bengkel, pelabuhan, pabrik, dan lain-lain.

Pada dasarnya yang dimaksud dengan pesawat angkat secara garis besarnya dapat dibagi dua bagian, yaitu:

\section{Hoesting machine}

\section{Conveing machine}

Pada pesawat angkat jenis hoesting machine dipergunakan ntuk mengangkat atau memindahkan muatan yang berjumlah tertentu secara sekaligus. Jenis ini meliputi antara lain crane, wrench, dongkrak, dan sebagainya, sedangkan jenis conveying machine diperguakan untuk memindahkan atau mengangkat muatan dalam satuan unit dan berlangsung kontinyu atau terus-menerus. Jenis ini meliputi antara lain hand track, conveyor, forklift, dan sebagainya. Dalam pemilihan pesawat angkat yang akan digunakan, biasana sangat ditentukan atau dipengaruhi oleh jenis muatan atau berat yang akan diangkat serta kapasitas angkatnya. Misalnya untuk memindahkan material (bulk material) dengan kapasitas dan kecepatan tertentu kita pergunakan conveyor.

\subsection{Permasalahan}

Dari paparan di atas, penulis akan melihat hal-hal apa saja yang harus diperhatikan dalam mendesain belt conveor untuk pencurahan material dengan kapasitas 125 ton per jam dam sabuk $400 \mathrm{~m}$.

\subsection{Tujuan Penulisan}

Tujuan utama dalam penulisan tugas akhir ini adalah untuk menghitung puli, rol, dan sabuk pada conveor untuk pencurahan material dengan kapasitas 125 ton per jam dan lebar sabuk $400 \mathrm{~mm}$. 


\subsection{Batasan Masalah}

Batasan masalah dengan pokok-pokok bahasan antara lain: puli penggerak, puli ekor, roll penumpu, dan sabuk bermuatan, roll penumpu abuk balik dan sabuk.

\section{Landasan Teori}

\subsection{Tipe-Tipe Conveyor}

Conveyor yang biasa digunakan terdiri dari beberapa macam tipe sebagai berikut:

- Belt Conveyor

- V-Bucket Conveyor

\section{- Pneumatic Conveyor}

Tipe belt dipergunakan untuk mengangkut muatan curah dan muatan unit. Pemakaian jenis ini dapat dipergunakan baik secara mendatar maupun mendaki miring. Tipe yang kedua yaitu $V$-belt conveyor hanya dapat digunakan untuk mengangkat material jenis curahan saja. Tipe pneumatic conveyor dipakai untuk memindahkan material yang sudah berbentuk bubuk halus karena tipe ini bekerja dengan hembusan (tenaga angin) sebagai penggeraknya.

\subsection{Jenis Muatan Conveyor}

Adapun penggolongan jenis muatan ini terbagi atas dua golongan, yaitu:

- Material curahan (bulk material)
- Material satuan (unit material)

Tergolong material curahan ini adalah material yang berbentuk butiran berupa timbunan atau curah seperti batu-batuan kecil, pasir, dan sebagainya. Sedangkan material berupa unit atau saluran adalah material yang bentuknya berdimensi (tidak berupa bongkahan) seperti karung (zak semen), balok kayu, peti, dan sebagainya.

Berdasarkan data yang ada dan pertimbangan dari penjelasan tadi serta material yang diangkat atau dipindahkan, maka jenis conveyor yang cocok untuk direncanakan adalah tipe belt-conveyor yang diharapkan akan dapat dipergunakan sesuai dengan kondisi lapangan kerjanya.

\subsection{Perhitungan Perencanaan Conveyor}

Pada perencanaan conveyor jenis ini kompoen-komponen yang akan diperhitungkan adalah:

1. Sabuk

2. Rol Penumpu

3. Puli penggerak/drum

4. Tegangan pada sabuk

5. Motor pengerak dan sistem transmisi

6. Poros-poros

7. Bantalan

8. Rangka 
III. Metodologi Penelitian

\subsection{Tempat dan Waktu Penelitian}

Tempat penelitian dilaksanakan di Bengkel Rahmad Jalan Imam Bonjol Gedong Air Bandar Lampung, BLK Kota Bandar Lampung dan LIPI Lampung yang berlokasi di Lampung Selatan. Waktu pe nelitian dilaksanakan dari tanggal 20 Januari 2017 - 20 September 2017.

\subsection{Data Penelitian}

Pengambilan data penelitian secara primer yaitu langsung pengambilan data pada saat belt conveyor diujicobakan pada pencurahan material.

\subsection{Perhitungan Penelitian}

Dalam penelitian ini dilakukan berbagai perhitungan, diantaranya:
A. Muatan Sabuk
B. Lebar Sabuk
C. Tebal dan Lapisan Sabuk
D. Berat Sabuk Per Satuan Panjang
E. Perhitungan Rol Penumpu
F. Perhitungan Pulli Penggerak
G. Perhitungan Tegangan pada Sabuk

H. Pemilihan Motor Penggerak dan Transmisi Sistem

I. Poros Pulli Ekor

J. Poros Rol Penumpu
K. Perencanaan Bantalan

L. Perhitungan Rangka

\section{Hasil Penelitian Dan Pembahasan}

\subsection{Hasil Penelitian}

\section{A. Muatan Sabuk}

Kapasitas tingkat untuk pengangkutan terak semen dapat dihitung dengan menggunakan rumus (Rudenko N., 2012) sebagai berikut:

$\mathrm{Q}=\mathrm{V} \times \mathrm{y}$ (ton/jam)

Dimana:

$$
\begin{aligned}
\mathrm{Q} & =125 \text { ton/jam } \\
\mathrm{y} & =\text { berat muatan (bulk/volume) } \\
& =1,0: 1,30\left(\text { ton } / \mathrm{m}^{3}\right) \\
& =1,30
\end{aligned}
$$

Volume angkut per jam adalah

$$
\begin{aligned}
\mathrm{V} & =\mathrm{Q} / \mathrm{y}\left(\mathrm{m}^{3} / \mathrm{jam}\right) \\
& =125 / 1,30 \\
& =96,15 \text { ton } / \mathrm{jam}
\end{aligned}
$$

Muatan per meter sabuk (g)

$$
\begin{aligned}
\mathrm{g}= & \frac{V x y}{v}(\mathrm{~kg} / \mathrm{m}) \\
v= & \text { kecepatan sabuk untuk terak } \\
& \text { semen } / \mathrm{jam} \\
= & 0,8: 1,0(\mathrm{~m} / \mathrm{det}) \\
= & 0,8 \mathrm{~m} / \mathrm{det} \ldots \ldots \ldots \ldots \ldots \ldots . . . . . . . \\
= & 2880 \mathrm{~m} / \mathrm{jam}
\end{aligned}
$$

Muatan per meter sabuk (g)

$$
\begin{aligned}
\mathrm{g} & =\frac{96,15 \times 1,30 \mathrm{ton} / \mathrm{m}}{2880} \\
& =0,0434 \mathrm{ton} / \mathrm{m} \\
& =43,4 \mathrm{~kg} / \mathrm{m}
\end{aligned}
$$




\section{B. Lebar Sabuk}

Lebar sabuk conveyor untuk

mengangkut terk semen ini dapat

diitung dengan menggunakan rumus

(Rudenko N., 2012) sebagai berikut:

B $\geq 2 \mathrm{a}^{\prime}+200(\mathrm{~mm})$

Dimana:

$$
\begin{aligned}
\mathrm{a}^{\prime} & =10: 600 \mathrm{~mm} \\
& =60 \mathrm{~mm}
\end{aligned}
$$

Maka lebar sabuk (B):

$$
\begin{aligned}
& \text { В } \geq 2(60)+200(\mathrm{~mm}) \\
& \text { В } \geq 2320 \mathrm{~mm}
\end{aligned}
$$

Untuk lebar sabuk direncanakan B > $320 \mathrm{~mm}$ dan disesuaikan dengan tabel standarisasi sabuk yaitu diambil B = $400 \mathrm{~mm}$.

\section{Tebal dan Lapisan Sabuk}

Untuk lebar sabuk B = 400 mm, maka jumlah lapisan sabuk yaitu:

$\mathrm{i}=3: 5$ lapisan

Untuk karakteristik beban terak semen ditentukan

- Tebal sisi terbeban $\quad: \delta_{1}=1,5$ : $3 \mathrm{~mm}$

- Tebal sisi balik $\quad: \delta_{2}=1,0$ $\mathrm{mm}$

Untuk tebal lapisan yang tidak mengandung karet $(\delta)$

$\delta \quad=1,25 \mathrm{~mm}$, sabuk serat katun
$=1,9: 2,0 \mathrm{~mm}$, sabuk kekuatan tertinggi

$=0,9: 1,4 \mathrm{~mm}$, sabuk bahan sintetis

Dapat ditentukan jumlah lapisan sabuk dan tebalnya (Rudenko N., 2012), yaitu, Lapisan sabuk (i):

(i) $=3: 5$ lapisan $=3$ lapisan

Tebal sabuk:

- Tebal sisi terbeban : $\delta_{1}=3,0$ $\mathrm{mm}$

- $\delta_{2}=1,0 \mathrm{~mm}$

- Tebal lapisan yang tidak mengandung karet $\delta_{2}=2,0 \mathrm{~mm}$

\section{Berat Sabuk per satuan panjang}

$\mathrm{g}_{\mathrm{b}} \quad=1,1 \mathrm{~B}\left(\delta_{1}+\delta_{2}+\delta_{3} \times \mathrm{i}\right)$

(kg/m) (Rudenko N., 2012)

Dimana:

$$
\begin{array}{ll}
\mathrm{B} & =400 \mathrm{~mm}=0,4 \mathrm{~m} \\
\delta_{1} & =2,0 \mathrm{~m} \\
\delta_{\mathrm{i}} & =3,0 \mathrm{~m} \\
\delta_{2} & =1,0 \mathrm{~m} \\
\mathrm{i} & =3 \text { lapisan }
\end{array}
$$

Maka:

$$
\begin{aligned}
\mathrm{g}_{\mathrm{b}} & =1,1 \times 0,4\{(2 \times 3)+3+ \\
& 1)\}(\mathrm{kg} / \mathrm{m}) \\
= & 4,4 \mathrm{~kg} / \mathrm{m}
\end{aligned}
$$




\section{E. Perhitungan Rol Penumpu}

Jarak roller pada sisi yang terbeban

$\left(\mathrm{I}_{\mathrm{i}}\right)$

Kapasitas per meter kubik (y) =

1,30 ton $/ \mathrm{m}^{3}$

Lebar sabuk

$=$

$400 \mathrm{~mm}$

Didapatkan jarak rol (1)

$=$

$1400 \mathrm{~mm}$

Untuk jarak rol pada daerah

pemuatan ke sabuk (Rudenko N.,

2012) adalah:

$$
\begin{aligned}
\mathrm{I}_{1} & =0,5 \times \mathrm{L}(\mathrm{mm}) \\
& =0,5 \times 1400 \mathrm{~mm} \\
& =700 \mathrm{~mm}
\end{aligned}
$$

Jarak roller pada sisi balik $\left(\mathrm{I}_{2}\right)$

$$
\begin{aligned}
\mathrm{I}_{2} & =21 \times \mathrm{L}(\mathrm{mm}) \\
& =21 \times 1400 \mathrm{~mm} \\
& =2800 \mathrm{~mm}
\end{aligned}
$$

Panjang rol untuk sisi balik (sisi lurus):

$$
\begin{aligned}
\mathrm{L} & =\mathrm{B} \times 100(\mathrm{~mm}) \\
& =400 \times 100 \mathrm{~mm} \\
& =500 \mathrm{~mm}
\end{aligned}
$$

\section{F. Perhitungan Puli Penggerak}

Puli penggerak ini berfungsi menggerakan atau memutar sabuk.

Puli ini terbuat dari bahan lempengan besi atau lat baja yang dibentuk seperti drum atau silinder dan ditengahnya diberi poros.
A. Panjang puli (Lp)

$\mathrm{Lp} \quad=\mathrm{B}+100(\mathrm{~mm})$

Dimana:

B $=$ Lebar sabuk $=400 \mathrm{~mm}$

Maka:

Lp $\quad=400+100 \mathrm{~mm}$ $=500 \mathrm{~mm}$

B. Diamater puli (Dp)

$\mathrm{Dp} \geq \mathrm{k} . \mathrm{i}(\mathrm{mm})$

$$
\text { Lp } \quad=\mathrm{B}+100(\mathrm{~mm})
$$

Dimana:

$$
\begin{aligned}
\mathrm{k} & =\text { Faktor proposional } \\
& =125: 150 \\
& =125 \\
\mathrm{i} & =\text { Jumlah lapisan sabuk } \\
& =3 \text { lapisan }
\end{aligned}
$$

Maka:

$$
\begin{aligned}
\text { Dp } & \geq \mathrm{k} . \mathrm{i}(\mathrm{mm}) \\
\text { Dp } & \geq 125 \times 3 \mathrm{~mm} \\
& \geq 375 \mathrm{~mm} \\
\text { Dp } & =375 \mathrm{~mm} \\
& =37,5 \mathrm{~cm} \\
& =0,375 \mathrm{~m}
\end{aligned}
$$

C. Putaran puli penggerak (n)

$$
\mathrm{N}=\frac{\mathrm{v} 60}{\pi \mathrm{Dp}}
$$

Dimana:

$$
\begin{aligned}
& \mathrm{V}=\text { kecepatan sabuk }=0,8 \\
& \mathrm{~m} / \mathrm{det} \\
& \mathrm{Dp} \quad=0,375 \mathrm{~m} \\
& \mathrm{~N} \quad=\underline{0,8 \times 60} \\
& \pi \times 0,375
\end{aligned}
$$




$$
\begin{aligned}
& =48 / 1,178 \\
& =40 \mathrm{rpm}
\end{aligned}
$$

\section{G. Perhitungan Tegangan pada Sabuk}

Conveyor yang direncanakan ini digunakan untuk mengangkat terak semen dimana panjang cnveor 22 meter dan sudut kenaikannya $15 \%$. Adanya sudut kenaikan ini menyebabkan gerakan mendaki dan menimbulkan tegangan. Tegangan pada belt coveyor terutama pada titik balik.

A. Pada sisi terbeban $\left(\mathrm{w}_{1}\right)$

$$
\begin{aligned}
& \mathbf{w}_{1}=\left(\mathbf{g}+\mathbf{g b}+\mathbf{g}_{\mathbf{p}}\right) \mathbf{L s} \mathbf{w}^{\prime} \cos \beta \pm \\
& \text { Ls } \sin \pm \boldsymbol{\beta})(\mathbf{k g}) \quad \text { (Rudenko } \\
& \text { N.2012) }
\end{aligned}
$$

B. Pada sisi balik $\left(\mathrm{w}_{1}\right)$

$$
\begin{aligned}
& w_{1}=\left(g b+g_{p}^{\prime}\right) L s w^{\prime} \cos \beta \pm \\
& \text { gb Ls sin } \pm \beta)(k g) \text { (Rudenko N. }
\end{aligned}
$$

Dimana:

$$
\begin{array}{ll}
\mathrm{w} & =\text { tahanan sabuk } \\
\mathrm{g} & =\text { berat beban }(\mathrm{kg} / \mathrm{m}) \\
\mathrm{gb} & =\text { berat sabuk }(\mathrm{kg} / \mathrm{m}) \\
\mathrm{gp} & =\text { berat rol penumpu }
\end{array}
$$

$(\mathrm{kg} / \mathrm{m})$

$\beta=$ sudut kemiringan conveyor pada sisi horizontal Ls = panjang sabuk $(\mathrm{m})$
Tanda (-) $\quad=$ arah gerakan sabuk ke bawah

Tanda $(+)=$ arah gerakan sabuk ke atas

$\mathrm{Wi}=$ koefisien tahanan sabuk pada rol

Gaya tarik efektif $\left(\mathrm{W}_{0}\right)$

$\mathrm{W}_{0}=\mathrm{S}_{\mathrm{t}}-\mathrm{S}_{1}+\mathrm{W}_{\mathrm{dr}}$

$(\mathrm{kg})$ (Ru

denko N., 2012)

$$
=649,96-312,48+38 \text {, }
$$

$4976(\mathrm{~kg})$

$$
=375,98 \mathrm{~kg}
$$

Daya untuk memutar puli penggerak $(\mathrm{N})$

$$
\mathrm{N}=\underline{\mathrm{W}}_{0} \underline{v}(\mathrm{Kw})
$$
...Ruden

ko N., 2012) 102

$$
\begin{aligned}
& =(375,98 \times 0,8): 102 \\
& =2,9 \mathrm{Kw} \\
& =3,887 \mathrm{Hp}
\end{aligned}
$$

Momen puntir yang terjadi $\left(\mathrm{M}_{\mathrm{t}}\right)$

$$
\begin{aligned}
& \text { a) } \mathrm{M}_{\mathrm{t}}=71620 \underline{\mathrm{N}} \quad(\mathrm{Kg}-\mathrm{cm}) \\
& \mathrm{n} \\
& =71620 \times(3,887: 40) \\
& =695,67 \mathrm{~kg} . \mathrm{cm} \\
& =69,6 \mathrm{~kg} \cdot \mathrm{m} \\
& \text { b) } \mathrm{M}_{\mathrm{t}}=\mathrm{W}_{0} \underline{\mathrm{Dp}} \quad(\mathrm{Kg}-\mathrm{cm}) \\
& 2 \\
& (\mathrm{D}=\text { diameter puli }=0,375 \mathrm{~m}) \\
& =375,98 \times(0,375: 2) \\
& =71 \mathrm{~kg} \cdot \mathrm{m}
\end{aligned}
$$




\section{H. Pemilihan Motor Penggerak dan} Transmisi Sistem

Untuk menggerakka puli dan sabuk pada perencanaan ini digunakan motor listrik dan untuk mentransimisikan daya dan putaran biasaya dilakukan dengan 3 cara:

1. Roda gigi dimana efisiensinya (

$$
=0,45: 0,97
$$

2. Ranta dimana efisiensinya $(\eta ́)$

$$
=0,97: 0,98
$$

3. Belt dimana efisiensinya (ท́)

$$
=0,94: 0,97
$$

Pada belt conveyor ini direncanakan menggunakan sistem transimisi roda gigi, hal ini disebabkan kapasitas yang diangkut cukup besar yaitu $=125$ ton/jam.

Daya motor listrik yang digunakan $\left(\mathrm{N}_{\mathrm{ml}}\right)$ :

$$
\mathrm{N}_{\mathrm{ml}}=\underline{\mathrm{N}}(\mathrm{Kw})
$$

(Rudenko N., 2012)

$$
\eta
$$

Dimana:

$$
\mathrm{N} \quad=\text { Daya yang diperlukan }
$$

utuk menggerakkan puli $=2,9 \mathrm{Kw}$

$$
\begin{aligned}
\eta & =0,45: 0,97 & & \text { (untuk roda gigi) } \\
& =0,85 & & \text { (direncanakan) }
\end{aligned}
$$

Maka:

$$
\begin{aligned}
\mathrm{N}_{\mathrm{ml}} & =\frac{2,9}{0,85}(\mathrm{Kw}) \\
= & 3,4 \mathrm{Kw}
\end{aligned}
$$

Jadi diameter poros puli penggerak:

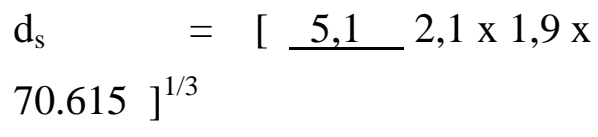

$$
5,2=65,1 \mathrm{~mm}
$$

Dimana syarat aman:

Ds puli penggerak $\leq \mathrm{ds}$ output reduction gear $\quad 65,1 \leq 75 \mathrm{~mm}$.

Untuk poros puli penggerak (diameter) pada perencanaan ini disamakan dengan poros output reduction gear (diameter).

Ds puli penggerak $=\mathrm{ds}$ reduction gear $=75 \mathrm{~mm}$

\section{Poros Puli Ekor}

$$
\mathrm{T} \quad=\left(9,74 \times 10^{5} \underline{\mathrm{Pd}}\right) \quad(\mathrm{kg}-\mathrm{mm})
$$
...(Catalogue No.2401E, 2012) $n$

Dimana:

$$
\begin{array}{ll}
\mathrm{Pd} & =2,9 \mathrm{Kw} \\
\mathrm{N} & =40 \mathrm{rpm}
\end{array}
$$

Maka:

$$
\begin{aligned}
& \mathrm{T} \quad=\left(\begin{array}{llll}
9,74 & \times 10^{5} & \underline{2,9}
\end{array}\right) \quad(\mathrm{kg}- \\
& \mathrm{mm} \text { ) } \\
& 40=70615 \mathrm{~kg}-\mathrm{mm}
\end{aligned}
$$

Bahan poros direncanakan JIS G-4051 s50C dengan $b=62 \mathrm{~kg} / \mathrm{mm}^{2}$, maka tegangan geser izin:

$$
\begin{gathered}
\tau_{\mathrm{a}} \quad=\frac{\delta b}{\ldots \ldots \ldots \ldots \ldots \ldots \ldots \ldots \ldots}\left(\mathrm{kg} / \mathrm{mm}^{2}\right) \\
\text { No.2401E, 2012) } \\
S_{f 1} x S_{f 2} \\
\mathrm{~S}_{\mathrm{f} 1}=6
\end{gathered}
$$




$$
\begin{aligned}
\mathrm{S}_{\mathrm{f} 2} & =1,3: 3,0 \\
& =2,0
\end{aligned}
$$

Maka:

$$
\begin{aligned}
A & =\frac{62}{6 \times 2}\left(\mathrm{~kg} / \mathrm{mm}^{2}\right) \\
& =5,2 \mathrm{~kg} / \mathrm{mm}^{2}
\end{aligned}
$$

Diameter poros puli ekor $\left(\mathrm{d}_{\mathrm{s} 1}\right)$

$\mathrm{d}_{\mathrm{s}}$

]$^{1 / 3}(\mathrm{~mm}) \quad$ (Catalogue No.2401E 2012)

\section{5,2}

Dimana:

$$
\begin{aligned}
& \mathrm{K}_{\mathrm{t}} \quad=1,5: 3,0 \\
& =2,1 \\
& \mathrm{C}_{\mathrm{b}} \quad=1,2: 2,3 \\
& =1,9 \\
& \mathrm{~d}_{\mathrm{s}} \quad=\left[\begin{array}{ll}
5,1 & 2,1 \times 1,9 \mathrm{x}
\end{array}\right. \\
& 70.615]^{1 / 3} \\
& 5,2=65,1 \mathrm{~mm}
\end{aligned}
$$

\section{J. Poros Rol Penumpu}

Dari perhitungan terdahulu didapat besar diameter rol penumpu $\mathrm{D}=18 \mathrm{~mm}$ dan panjang roller pada sisi balik/lurus $\mathrm{L}=$ $500 \mathrm{~mm}$.

Untuk rol-rol penumpu pada sisi beban dianggap pembebanan terpusat di bagian tengah rol penemu. Lebar atau panjang rol penumpu pada bagian tengah adalah:

$$
\begin{aligned}
\mathrm{L}_{1} & =0,4 \mathrm{~L} \\
& =0,4 \times 50 \\
& =200 \mathrm{~mm}
\end{aligned}
$$

Gaya berat yang diterima oleh poros adalah:

$\operatorname{Pr}=$ Berat roller + Berat

badan + Berat sabuk

Dimana:

Berat roller penumpu per meter

$\left(g_{p}^{\prime}\right)=7,86 \mathrm{~kg}$

Berat beban per meter $(\mathrm{g})$

$=43,4 \mathrm{~kg}$

Berat sabuk per meter

$$
=4,4 \mathrm{~kg}
$$

Maka:

$$
\begin{aligned}
\operatorname{Pr} & =\left(g_{p}^{\prime}+g+g_{b}\right) \mathrm{kg} \\
& =(7,86+43,4+4,4) \mathrm{kg} \\
& =55,66 \mathrm{~kg}
\end{aligned}
$$

Tegangan geser yang terjadi:

$\tau_{\mathrm{a}} \quad=\delta b\left(\mathrm{~kg} / \mathrm{mm}^{2}\right)$ (Catalogue

No.2401E, 2012)

$$
S_{f 1} \times S_{f 2}
$$

Dimana:

$$
\begin{array}{ll}
\delta \mathrm{b} & =62 \mathrm{~kg} / \mathrm{mm}^{2} \\
\mathrm{~S}_{\mathrm{f} 1} & =8 \text { (Faktor keamanan }
\end{array}
$$

untuk beban statis)

$\mathrm{S}_{\mathrm{f} 2}=4$ (Faktor keamanan untuk beban dinamis)

Maka:

$$
\begin{aligned}
\tau_{\mathrm{a}} & =\frac{62}{6 \times 4}\left(\mathrm{~kg} / \mathrm{mm}^{2}\right) \\
& =2,583 \mathrm{~kg} / \mathrm{mm}^{2}
\end{aligned}
$$

Diameter poros roller (dsr)

$$
\left.\begin{array}{l}
\mathrm{d}_{\mathrm{sr}} \\
(\mathrm{mm})
\end{array} \quad=\frac{\left[\frac{10,2}{\mathrm{a}}\right.}{} \mathrm{M}_{\text {maks }}\right]^{1 / 3}
$$




$$
\begin{aligned}
\mathrm{d}_{\mathrm{sr}} \quad & =\left[\frac{10,2}{2,583} 5566\right]^{1 / 3} \\
& =28 \mathrm{~mm}
\end{aligned}
$$

\section{K. Perencanaan Bantalan}

Bantalan yang digunakan untuk belt conveyor adalah bantalan bola yang sesuai denga kondisi lapangan sera dapat beruur panjang atau lama.

Perhitungan bantalan puli

Direncanakan sama dengan puli ekor, sedangkan gaya yang bekerja pada bantalan itu adalah gaya radial.

$$
\begin{array}{ll}
\mathrm{P} & =\mathrm{X} \mathrm{F}_{\mathrm{r}}+\mathrm{Y} \mathrm{F}_{\mathrm{a}} \\
\mathrm{P} & =\text { Beban ekuivalen bantalan } \\
\mathrm{F}_{\mathrm{r}} & =\text { Beban radial konstan } \\
\mathrm{F}_{\mathrm{a}} & =\text { Beban aksial konstan }(=0) \\
\mathrm{X} & =\text { Faktor bantalan radial }=1 \\
\mathrm{Y} & =\text { Faktor bantalan aksial }=0
\end{array}
$$

Jadi:

$$
\begin{aligned}
\mathbf{P} & =\mathbf{F}_{\mathbf{r}} \\
& \Sigma \mathrm{F}_{\mathrm{v}}=0 \\
& \mathrm{R}_{\mathrm{A}}-\mathrm{P}+\mathrm{R}_{\mathrm{B}}=0
\end{aligned}
$$

Dimana:

$$
\mathrm{F} \quad=\text { Beban maksimum pada }
$$

poros puli

$$
=\text { Beban puli }+ \text { berat poros }
$$

+ berat beban + berat sabuk

Diameter puli $(\mathrm{Dp}) \quad=375 \mathrm{~mm}$

Panjang puli $(\mathrm{Lp}) \quad=500 \mathrm{~mm}$

Tebal puli $(\mathrm{t}) \quad=5 \mathrm{~mm}$ (d) $=375 \mathrm{~mm}-(2 \mathrm{x}$

10) $\mathrm{mm}$

$$
=355 \mathrm{~mm}
$$

Maka umur nominal:

$$
\begin{aligned}
\mathrm{L} & =\frac{60.40 .25 \cdot 000}{1.000 .000} \\
& =60 \text { millions of revolution }
\end{aligned}
$$

Kapasitas beban dinamik

$$
\begin{aligned}
\mathrm{C} / \mathrm{P} & =\mathrm{L}^{1 / \mathrm{p}} \\
\mathrm{C} & =\mathrm{P} \cdot \mathrm{L}^{1 / \mathrm{p}} \\
& =53,3(60)^{1 / 3} \\
& =208,66 \mathrm{~kg} \\
& =460,2 \mathrm{Lb}
\end{aligned}
$$

Data-data di atas berdasarkan SKF Ball and Roller Bearings Catalogue No. 2401 E Hal. 88. Bantalan yang dipilih ini aman sekali untuk digunakan karena:

$$
\geq \mathrm{C}
$$

$7500 \mathrm{lb} \geq 4602 \mathrm{lb}$

Putaran maksimum yang diizinkan (ń) $\geq$ putaran yang terjadi (n).

$8400 \mathrm{rpm} \geq 40 \mathrm{rpm}$

\section{Perhitungan bantalan idler roller}

Beban yang diterima bantalan idler roller ini adalah bebn radial

$$
\mathbf{P}=\mathbf{F r}
$$

Dimana:

$\mathrm{F}=$ Berat idler roller + Berat beban

+ Berat sabuk

$\begin{array}{ll}\text { Berat idler roller }\left(\mathrm{G}^{\prime} \mathrm{p}\right) & =11,00 \mathrm{~kg} \\ \text { Berat beban }(\mathrm{g}) & =30,38 \mathrm{~kg} \\ \text { Berat sabuk }(\mathrm{gb}) & =3,08 \mathrm{~kg}\end{array}$


Fr $\quad=(11+30,38+3,08) \mathrm{kg}$

$$
=44,5 \mathrm{~kg}
$$

Kapasitas beban diamik (C)

$$
\mathrm{C} \quad=\mathrm{P} . \mathrm{L}^{1 / \mathrm{p}}
$$

Dimana:

$$
\begin{array}{ll}
\mathrm{P} & =\mathrm{Fr} \quad=44,5 \mathrm{~kg} \\
\mathrm{P} & =3 \text { untuk ball bearing } \\
& =10 / 3 \text { untuk roller bearing }
\end{array}
$$

Putaran roller per menit (n):

$$
\begin{aligned}
\mathrm{v} & =\frac{\pi \cdot \mathrm{ds} \cdot \mathrm{n}}{60} \\
\mathrm{n} & =\frac{60 \cdot \mathrm{v}}{\pi \cdot \mathrm{ds}}
\end{aligned}
$$

Dimana:

$$
\begin{array}{ll}
\mathrm{v} & =\text { kecepatan sabuk }=0,8 \mathrm{~m} / \mathrm{det} \\
\mathrm{dsr} & =\text { diameter poros ruler }=28 \mathrm{~mm}
\end{array}
$$$$
=0,028 \mathrm{~m}
$$

Maka:

$$
\begin{aligned}
\mathrm{n} & =\frac{60 \times 80}{\pi \times 0,028} \\
= & 546 \mathrm{rpm} \\
\mathrm{L} \quad= & \frac{60 . \mathrm{n} \cdot \mathrm{Lh}}{1.000 .000}
\end{aligned}
$$

Dimana:

$$
\begin{aligned}
\mathrm{Lh} & =25.000 \mathrm{jam} \\
\mathrm{n} & =546 \mathrm{rpm}
\end{aligned}
$$

Jadi:

$$
\begin{aligned}
\mathrm{L} & =\frac{60 \times 546 \times 25.000}{1.000 .000} \\
& =819 \text { millions of revolutions }
\end{aligned}
$$

Kapasitas beban dinamik:

$$
\begin{aligned}
\mathrm{C} & =\mathrm{P} . \mathrm{L}^{1 / \mathrm{p}} \\
& =44,5 \times 819^{1 / 3}
\end{aligned}
$$

$$
\begin{aligned}
& =416,346 \mathrm{~kg} \\
& =918,044 \mathrm{Lb}
\end{aligned}
$$

\section{Perhitungan Rangka (Frame)}

Kerangka utama conveyor yang akan digunakan direncanakan mampu menahan beban yang terjadi pada rangka, tidak terlalu rumt dalam pembuatan dan perawatannya. Beban-beban yangang diterima rangka berasal dari beban muatan yang dipindahkan, peralatanperalatan utama dan perlengkapannya.

A. Berat Puli $\left(\mathrm{P}_{\mathrm{I}}\right)$

Dari hasil perhitungan sebelumnya berat puli ekor sama dengan berat puli penggerak, yaitu:

$$
\begin{aligned}
\mathrm{P}_{1} & =(44,887+7,48) \mathrm{kg} \\
& =52,367 \mathrm{~kg}
\end{aligned}
$$

B. Berat Sabuk

Berat sabuk per meter $=4,4 \mathrm{~kg} / \mathrm{m}$ Panjang sabuk keseluruhan:

$$
\text { Ls } \quad=(2 \pi \text { Dp })+(2 \text { Lo }) \mathrm{m}
$$

Dimana:

$\mathrm{Dp}=375 \mathrm{~mm}=0,375 \mathrm{~m}$

Lo $\quad=22 \mathrm{~m}$

Ls $\quad=2 \pi(0,375)+(2 \times 22) \mathrm{m}$ $=46,356 \mathrm{~m}$

Jadi:

$$
\text { Gs } \quad \begin{aligned}
& =\operatorname{Ls} \times g p(\mathrm{~kg}) \\
& =46,356 \times 4,4 \\
& =203,966 \mathrm{~kg}
\end{aligned}
$$


C. Berat Muatan $(\mathrm{Gm})$

Berat muatan per meter (g)

$\mathrm{G} \quad=43,40 \mathrm{~kg} / \mathrm{m}$

Jadi:

$$
\begin{aligned}
\mathrm{Gm} & =\mathrm{g} \times \mathrm{Lo} \\
& =43,4 \times 22 \\
& =954,80 \mathrm{~kg} \\
\epsilon \quad & =0,0267 / 1100 \\
& =2,427 \cdot 10^{-5}
\end{aligned}
$$

Maka tegangan yang terjadi :

$$
\begin{aligned}
& =\mathrm{E} . \epsilon \\
& =2,12 \times 10^{6} \times 2,427.10^{-5} \\
& =51,45 \mathrm{~kg} / \mathrm{cm}^{2}
\end{aligned}
$$

Untuk mendapatkan bulan yang aman maka tegangan yang terjadi dikalikan dengan faktor keamanan :

$$
=\mathrm{Sf}
$$

Dimana :

$$
\begin{aligned}
\text { Sf } & =6 \\
& =(51,45 \times 5) \\
& =308,7 \mathrm{~kg} / \mathrm{cm}^{2}
\end{aligned}
$$

Maka bahan yang dipilih untuk rangka ini SII.0233-79. Simbol V-60-BJ34

Dimana tegangan yang diizinkan :

$$
\begin{aligned}
& =33 \mathrm{~kg} / \mathrm{mm}^{2} \\
& =3300 \mathrm{~kg} / \mathrm{cm}^{2}
\end{aligned}
$$

Syarat aman :

$$
3300 \mathrm{~kg} / \mathrm{cm}^{2} \geq 308,7 \mathrm{~kg} / \mathrm{cm}^{2}
$$

Defleksi yang diizinkan

$$
\leq 0,0015 \mathrm{~L} \quad \mathrm{~L}=11 \mathrm{~m}=1100
$$

meter

$$
\begin{aligned}
& \leq 0,0015 \times 1100 \\
& \leq 1,65 \mathrm{~cm}
\end{aligned}
$$

Syarat aman :

$1,65 \geq 0,0267 \mathrm{~cm}$

\section{Kesimpulan Dan Saran}

\subsection{Kesimpulan}

Setelah dilakukan perhitunganperhitungan pada setiap bab terdahulu dapat disimpulkan dimensi pada perencanaan belt conveyor sebagai berikut:

A. Kapasitas

1. Kapasitas angkut (Q) : 125 ton/jam

2. Kapasitas per meter (g) : 0,0434 ton $/ \mathrm{m}$

3. Volume angkut per jam (v) : 96,154 ton/jam

B. Sabuk

1. Lebar Sabuk (B): $400 \mathrm{~mm}$

2. Tebal Sabuk $(\delta): 6 \mathrm{~mm}$

3. Panjang Sabuk: $22.000 \mathrm{~mm}$

C. Puli

1. Diameter puli (Dp) : $375 \mathrm{~mm}$

2. Panjang puli (Lp) : $500 \mathrm{~mm}$

3. Putaran puli $\left(\mathrm{n}_{\mathrm{p}}\right): 40 \mathrm{rpm}$

D. Rol Penumpu

1. Diameter (Dr) : $108 \mathrm{~mm}$

2. Panjang (Lr) : $500 \mathrm{~mm}$

E. Frame

1. Standarisasi SII.0233-79, baja canai bertepi bulat canai panas dengn simbol V-60

2. Bahan BJ34 
F. Motor Penggerak

1. Motor listrik : Merk HITACHI

2. Tipe : TFC, 3-phase 200-600V, $50 / 60 \quad \mathrm{~Hz} \quad$ IEC Standard

3. Frame size : TFOL - $132 \mathrm{MF}$

4. Daya Output : 7,5 Kw - 4 pole

5. Putaran : $800 \mathrm{rpm}$

G. Reduction Gear

1. Merk produksi : Bellpony

2. Perbandingan Transimisi : $1 / 20$

3. Daya Input : $17,82 \mathrm{Kw}$

4. Tipe: PA 50

5. Putaran input : $800 \mathrm{rpm}$

\subsection{Saran}

Untuk memperoleh hasil/kemampuan yang maksimal dari suatu belt conveyor, hal-hal yang harus diperhatikan adalah penggunaan puli, sabuk, rol, frame, dan motor. Perhitungan dan penentuan komponen tersebut harus dilakukan secara cermat dan seksama.

\section{Daftar Pustaka}

Anonym.2012. SKF, Ball and Roller Bearings, Catalogue No.2401E

Darkov A, Kuznetsop. V. 2012. Structural Mechanics, Second Edition, Mir Publishers Moscow.

Iunkovsky N., 2013. Conveying Crushing, Washing Screening, Machnary, Mir Publishers Moscow.

Rudenko N., 2012.Materials Handling Equipment, Second edition Mir Publishers Moscow

Spivakovsky and Dyachkov. 2013. Conveyor and Related Equipment, Peace Publishers Moscow

Sularso dan Kiyokatsu Suga. 2014. Elemen Mesin, Cetakan Keempat Pradnya Pramita, Jakarta.

Timoshenko S.. 2013. Stength of Materials, Edisi Ke Tiga. Robert E, Krieger Publishing Compan Huntington, New York 